\title{
O papel do professor na formação do bacharel em turismo: um estudo de caso
}

\author{
Bernadete Neves Mesquita ${ }^{1}$ \\ detemesquita@yahoo.com.br \\ Jersone Tasso Moreira Silva ${ }^{2}$ \\ tasso@facefumec.br \\ Andréa Lourdes Ribeiro ${ }^{3}$ \\ andrearibeiro2004@yahoo.com.br
}

\section{Resumo}

Analisa-se, no presente estudo, a importância do papel do professor para o curso de Turismo, sua interferência, contribuição e participação na formação do bacharel, além da percepção do aluno com relação a esse profissional. Por isso, o objetivo foi investigar a interferência desse professor no processo de formação profissional, além de avaliar a percepção do docente em relação ao discente. Para tanto, procedeu-se à análise dos dados levantados a partir da aplicação de 42 questionários válidos, contendo 29 perguntas, aplicados aos alunos. Esse percentual de amostra permite tecer considerações que sinalizam um perfil claro e objetivo do corpo docente do curso em estudo. Para os professores, foram aplicados 12 questionários em um universo de 13, contendo 52 questões. Os questionários forneceram informações sobre os aspectos referentes à contribuição

\footnotetext{
${ }^{1}$ Mestre em Turismo e Meio Ambiente do UNA, pós-graduada em Gestão Hoteleira pelo Centro Universitário Newton Paiva Ferreira e professora substituta do Cefet/MG.

${ }^{2}$ Doutor pela Universidade Federal de Viçosa (UFV), professor adjunto IV do Programa de Mestrado e Doutorado em Administração da Universidade Fumec.

${ }^{3}$ Doutora em Estudos Linguísticos pela UFMG, atualmente desenvolve pesquisa com foco na formação de professores para o ensino superior.
}

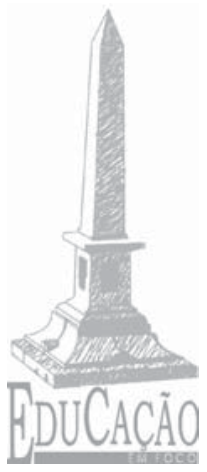

41 
desse professor para o curso; à infraestrutura da Instituição de Ensino Superior (IES); ao projeto pedagógico, além da avaliação dos processos de avaliação durante a formação desse aluno. Os resultados da pesquisa confrontados com o referencial bibliográfico utilizado revelaram alguns dados que podem ser destacados, tais como: os professores do referido curso foram muito bem avaliados com relação ao preparo antecipado das aulas, obtendo quase que unanimidade, eles expõem com clareza os conteúdos e oferecem informações adequadas. Outro ponto observado está na questão do aproveitamento dos professores que atuam como coordenadores de outros cursos para ministrarem aulas no curso de Turismo, estratégia que vem sendo positiva até agora, pois percebeu-se que esse profissional está atento ao processo de formação do aluno como um todo. Tais profissionais, além de terem participado ativamente da confecção do projeto pedagógico, conhecem amplamente a IES, o que contribui ainda mais para uma visão sistêmica do curso. É importante destacar que a infraestrutura disponibilizada pela instituição estudada contribuiu positivamente para a satisfação dos alunos com relação ao curso e às atividades práticas propostas tanto em laboratórios como também a execução de inventários e eventos idealizados pelos próprios alunos. Por fim, é importante enfatizar que o caráter exploratório desse estudo abre a possibilidade para a realização de uma série de novas pesquisas sobre o papel do professor para o curso de turismo. Concluiu-se, então, que há necessidade de informar ao professor que ministra aulas no curso sobre: a profissão e a área de atuação do profissional em formação que poderá ocorrer a partir de cursos, participações em congressos e feiras, além da participação efetiva em atividades promovidas pelo curso.

Palavras-chave: Turismo; docentes; discentes; projeto pedagógico. 


\section{Introdução}

O estudo de caso em questão foi elaborado para dar suporte ao projeto pedagógico que se encontrava em elaboração a fim de que o curso de turismo passasse pelo reconhecimento, Instituição de Ensino Superior (IES) que se encontra no estado de Minas Gerais. O estudo tinha como principal objetivo discutir sobre as possíveis causas para a falta de respeito ou até mesmo de compromisso com relação ao curso, questão levantada pelos discentes e docentes da própria instituição. Até mesmo a direção da escola nutria esse sentimento com relação ao curso, sentimento que parece uma constante nos alunos e professores dos cursos de turismo e que motivou este estudo. Quais seriam as causas desse sentimento? Poderiam estar ligados aos professores envolvidos no processo de ensino e aprendizagem? Por isso a importância deste trabalho para os estudiosos da atividade turística. Poderia ser o professor um agente negativo nesse processo? Teria o aluno um perfil específico pautado no "descompromisso" para com os estudos e para com a sua futura profissão ao se candidatar a esse curso? Ou teriam as instituições de ensino alguma responsabilidade sobre o assunto? $\mathrm{O}$ que exatamente motivaria esse sentimento de "descompromisso" com o curso e a atividade turística? Essas perguntas são recorrentes e incomodam há muitos anos, sendo uma constante no trade turístico e para os acadêmicos.

O presente artigo, motivado pelas perguntas acima, foi desenvolvido a partir da revisão da literatura somada à análise dos dados obtidos pelos questionários. Ele teve como objetivo tratar de alguns aspectos sobre o papel do professor na construção da identidade do futuro profissional. Sua interferência no processo tanto do ensino como da aprendizagem pode contribuir com os cursos, com as IES, com os docentes e com os discentes do curso de turismo a partir do conhecimento de situações relacionadas à educação com ênfase na atividade turística.

Dessa forma, a análise dos dados coletados permitiu avaliar e

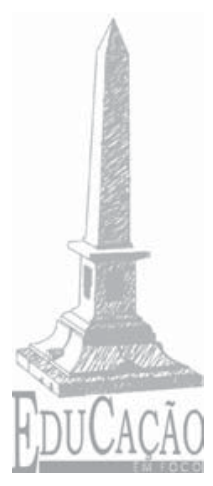


contextualizar situações acadêmicas com foco nas atitudes e papéis desenvolvidos a princípio pelos professores do curso. Porém, não há como avaliar o processo educacional sem observar além do agente transformador, a atitude daquele que sofre a ação de ser transformado. Os papéis se misturam e não se tem a clareza de quem transforma quem. Assim achou-se necessário que todas as partes do processo fossem ouvidas para maior embasamento.

Alguns levantamentos foram feitos para embasar o estudo, voltando para a história dos cursos de turismo que iniciaram suas atividades no Brasil há pouco mais de trinta e cinco anos. Ao contrário de outros países que iniciaram seus estudos sobre a área há mais tempo. Porém, ao longo dos anos, esses cursos se destacaram no cenário educacional nacional, despertando o interesse pela área educacional e principalmente pela atividade turística em geral.

Nos primeiros anos de funcionamento dos cursos de turismo, observou-se uma procura acentuada por eles. Isso, de certa maneira, aguçou o espírito empreendedor dos empresários da educação que buscaram a abertura de novos outros cursos, aumentando a oferta (TRIGO, 1998). O turismo é considerado um curso de investimento e manutenção relativamente baratos, são cursos chamados de "cuspe e giz", que não exigem maiores investimentos em laboratórios caríssimos. Isso aguça ainda mais a ganância dos donos de instituições educacionais: ganhar dinheiro a um custo baixo. Talvez a falta de conhecimento sobre a atividade turística leve a essa atitude errônea por parte dos empresários. Eles consideram que a atividade turística é feita com a teoria em sala de aula, no entanto, ela requer visitas técnicas orientadas pelos professores e isso significa gastos relacionados a horas de trabalho desse profissional, transporte utilizado, hospedagem, alimentação dentre outros. Só assim o aluno se sentirá seguro em atuar nessa atividade. O aluno precisa perceber a atividade turística de forma concreta, com exemplos "vivos", para que não se torne um curso de imaginação e criatividade. Imaginar uma situação turística é diferente de senti-la no momento em que está ocorrendo. Além disso, deve-se 
levar em consideração o discente, que muitas vezes nunca teve a oportunidade de sair da sua cidade ou até mesmo de se frequentar qualquer tipo de meio de hospedagem. Como essa pessoa poderia de uma hora para outra perceber as variáveis que envolvem a atividade turística sem nunca ter feito parte dela?

As IES que buscam apenas a recompensa financeira, sem se preocupar com a qualidade do curso que estão oferecendo, perdem o real foco da atividade em questão. Elas apostam em cursos que oferecem poucos laboratórios ou apenas o espaço destinado aos mesmos, sem a participação real do discente com potencial suficiente para realizar projetos e se destacar como profissional no mercado de trabalho. A IES precisa oferecer laboratórios e apoiar a possibilidade de crescimento do aluno, acreditando no seu potencial e apostando no seu desenvolvimento para que ele desempenhe seu papel na sociedade antes de sair para o mercado de trabalho. Acredita-se que, enquanto o aluno estiver matriculado na faculdade, deverá ter garantido o acompanhamento de um ou mais professores para sugerir atividades e intervir em projetos, trabalhando em questões de relevância para a sua formação. Essas questões encarecem o curso e geram o descontentamento dos dirigentes das IES, trazendo consigo a desmotivação em investir no curso e torná-lo ainda mais atraente e coeso, unindo teoria aplicada em sala de aula e prática ou avaliação in locco das reais possibilidades turísticas da localidade.

\section{Histórico do curso em questão}

No caso específico deste trabalho, tem-se o seguinte histórico dos professores que já atuaram no curso e que atuam até hoje: na autorização para o funcionamento, eram seis professores, todos com curso de pós-graduação, sendo dois doutores, três mestres e uma especialista. Esse grupo de professores passou pelas entrevistas da comissão de especialistas e teve o curso aprovado pelo Instituto Nacional de Estudos e Pesquisas Educacionais Anísio Teixeira (INEP).

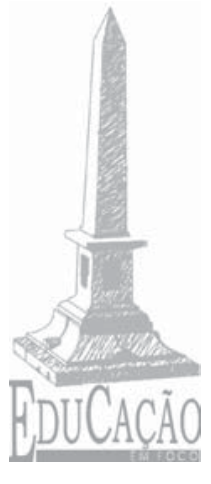

45 
O primeiro vestibular foi em dezembro de 2003. Foram 286 candidatos para o curso, que ofertava 120 vagas distribuídas entre manhã e noite. A IES optou por oferecer um vestibular por ano, sempre no final de cada ano. No primeiro vestibular, o curso de turismo teve uma procura excepcional, chegando a fechar duas turmas previstas com sessenta alunos em cada turno (manhã e noite). Esses alunos encontram-se atualmente no $7^{\circ}$ período. Houve algumas desistências durante o percurso devido a fatores variados, entre eles: dificuldades financeiras e falta de perfil para a atividade turística.

Em novembro de 2006, o curso obteve seu reconhecimento, tendo alcançado a nota máxima, cinco, na avaliação feita pela comissão de especialistas que visitou a IES. Atualmente, o curso conta com a colaboração de 13 professores com a seguinte titulação: três doutores, oito mestres, dois especialistas. Todos possuem experiência de no mínimo quatro anos no exercício do magistério, vieram de cursos diversos, inclusive de cursos de turismo de outras IES. Dentre eles, tem-se: dois bacharéis em turismo, com experiência em outros cursos de turismo e também do trade turístico, tendo atuado em diversos segmentos da atividade turística; uma bacharel em hotelaria com mais de vinte anos de prática em hotéis, possuindo amplo conhecimento no setor, tanto de hotelaria como de alimentos e bebidas, sendo a responsável pelas disciplinas dessas áreas.

Alguns docentes estão no curso desde a sua aprovação. Dentre eles, a coordenadora, que recebeu a primeira comissão de especialistas, e outros docentes de diferentes áreas, que também estavam presentes na mesma época e se encontram no curso até o momento atual. Em termos de estabilidade, percebe-se que o curso vem se mantendo estável e oferece aos professores, com mais de dois anos de convivência, novas disciplinas dentro do seu potencial acadêmico. No início de cada semestre, os professores têm reuniões para discutir a inserção de cada conteúdo na estrutura do curso bem como o planejamento de trabalhos multi e interdisciplinares.

Nessas reuniões, decidem-se, além dos trabalhos 
interdisciplinares, apresentações em bancas, trabalhos práticos, visitas técnicas entre outras ações a serem implementadas nos próximos semestres. Outro ponto a ser destacado está relacionado à facilidade de aquisição de livros, CD's e DVD's, entre outros materiais didáticos. Cada professor contribui com suas sugestões, que são passadas ao coordenador e encaminhadas para os diretores. A maioria das sugestões tem a aprovação e é encaminhada ao setor de compras e para a bibliotecária, que procede a esse encaminhamento. Os livros adquiridos passam a constituir o acervo.

\section{Metodologia}

A metodologia aplicada neste estudo é de uma pesquisa exploratória de caráter quantitativo e qualitativo, com o intuito de obter conhecimentos mais apurados sobre a influência dos docentes que ministram aulas no curso.

De acordo com Richardson (1999), o método quantitativo caracteriza-se pelo emprego da quantificação tanto nas modalidades de coleta de informações quanto no tratamento dessas informações por meio de técnicas estatísticas. Já a abordagem qualitativa, justifica-se por ser uma forma adequada para entender a natureza de um fenômeno social.

Portanto, como uma pesquisa exploratória, o que se pretende não é fazer generalizações empíricas, mas proporcionar um levantamento de novas questões e uma exploração de outros entendimentos e interpretações dos resultados para que possam ser utilizados em futuras pesquisas sobre o tema.

Quanto aos meios, decidiu-se pela realização de pesquisa bibliográfica e de levantamento de dados. Conforme Gil (2002), a pesquisa bibliográfica é desenvolvida com base em material já elaborado. Dessa forma, no trabalho apresentado, buscaram-se os temas abordados em livros e artigos científicos. Ainda como define o autor, a pesquisa de levantamento caracteriza-se pela interrogação direta das pessoas cujo comportamento se deseja conhecer e, nesse

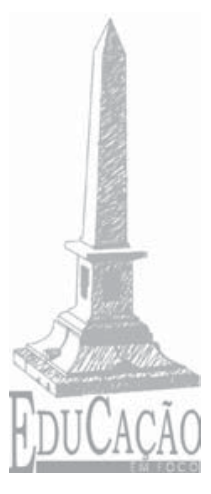


sentido, o levantamento foi realizado com os alunos dos seguintes períodos: $3^{\circ}, 5^{\circ}$ e $7^{\circ}$ de uma IES e também com os docentes que ministram aulas nesses períodos, além dos professores do $1^{\circ}$ período.

Os alunos do $1^{\circ}$ período foram excluídos por terem tido pouco contato com os professores e ainda não possuírem embasamento para participar de tal estudo.

A partir do relato de Costa (2001), o nível qualitativo ordinal configura-se como o mais adequado para se medir variáveis que visam mensurar opiniões. Todas as variáveis dos questionários têm o objetivo de mensurar opiniões.

Cada categoria ordinal individual em que essas variáveis qualitativas foram mensuradas e tabuladas segundo a quantidade de opiniões (utilizando o nível intervalar, uma vez que essa quantificação é discreta), assim a mensuração de cada variável gerou uma tabela com dados absolutos.

Os principais instrumentos de avaliação utilizados foram os questionários (um aplicado aos discentes e o outro aos docentes). Esses questionários revelam também o caráter exploratório da pesquisa.

Os alunos que responderam ao questionário foram orientados a não se identificarem. Foram aplicados 57 questionários a todos os discentes do curso de turismo presentes no período compreendido entre abril e maio de 2007, divididos em quatro turmas: uma de $3^{\circ}$ período (noite), uma de $5^{\circ}$ período (noite) e duas de $7^{\circ}$ período (manhã e noite). Os períodos não estavam em sequencia, pois a IES em estudo adota apenas um processo seletivo anual, porém o regime é semestral.

Dos 57 questionários aplicados, 15 foram descartados devido a erros em seu preenchimento. As instruções passadas antes da aplicação preconizavam que a avaliação deveria ser direcionada a todos os professores do curso, de uma maneira geral. Os questionários descartados foram aqueles em que os alunos avaliaram um único professor, explicitando o seu nome. Na maioria das vezes, esses alunos, cujos questionários foram descartados, se referiam ao seu professor preferido e raramente a um professor desafeto. 
Outros cinco questionários foram anulados por conterem mais de uma marcação por questão, não deixando claro o real posicionamento com relação ao que se solicitava. Assim, foram analisadas 29 variáveis (correspondentes às 29 questões do questionário) de um total de 42 questionários válidos, que correspondem ao número de alunos matriculados, configurando-se como uma amostra considerável do curso. Esse percentual de amostra permite tecer considerações que sinalizam um perfil claro e objetivo do corpo docente do curso em estudo.

Das 29 questões abordadas, dez (pouco mais de um terço) estão na região do quartil Q4 (acima de 75\%), o que permite fazer análises praticamente conclusivas. Outras 11 questões estão na região da metade superior do quartil Q3 (entre $62,5 \%$ e $75 \%$ ), o que permite fazer análises que sugerem tendências, porém com um grau de certeza menor. As oito questões restantes pertencem à metade inferior do quartil Q3 (entre 50\% e 62,5 \%), razão pela qual não permitem fazer um diagnóstico confiável. Foi utilizado o programa Excel com seu pacote de 62 ferramentas estatísticas e de formatação condicional. A partir do uso dessas ferramentas, estabeleceram-se três critérios para análise:

1. Os valores de categorias de variáveis que ficaram calculados entre $50 \%$ e $62,5 \%$ (metade inferior do quartil Q3) sinalizam que nenhuma análise pode ser feita. Nesse caso, pela proximidade da região de probabilidades atribuídas ao puro acaso;

2. Os valores de categorias de variáveis que ficaram calculados entre $62,5 \%$ e $75 \%$ (metade superior do quartil Q3) apontam que uma análise inicial pode ser feita, sinalizando uma tendência. Contudo, devido à relativa proximidade com a região de probabilidades atribuídas ao acaso, nenhuma conclusão segura pode ser considerada;

3. Os valores de categorias de variáveis que ficaram calculados acima de 75\% (quartil Q4) indicam que o valor sinaliza uma tendência clara de opinião, que não pode ser atribuída ao puro acaso.

Para a análise estatística dos dados, utilizou-se a teoria das

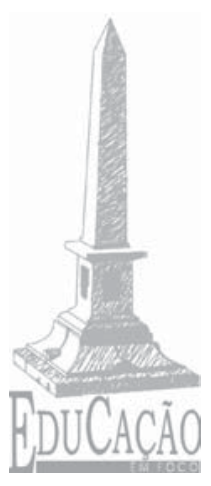


probabilidades associada ao critério de quartil (Q1: de 0 a 25\%; Q2: de 25 a 50\%; Q3: de 50 a 75\% e Q4: de 75 a 100\%). Uma vez que a simplificação resultou em apenas duas categorias de análise, qualquer valor situado próximo a $50 \%$ pode ser atribuído ao puro acaso. Assim, optou-se por analisar apenas as variáveis cujas medidas de categorias não pudessem ser atribuídas ao acaso. Sendo assim, é interessante para a pesquisa o quartil Q4 (acima de 75\%), que vai sinalizar uma tendência clara. No caso da variável exemplo, $98 \%$ dos alunos consideram que os professores preparam antecipadamente as suas aulas, sempre ou na maioria das vezes.

\section{A análise dos dados do questionário discente}

A título de exemplo, escolheu-se a variável "Preparo para a aula" (que responde a pergunta: "Você considera que os professores preparam antecipadamente as suas aulas?") utilizada no questionário discente. Como todas as outras variáveis, ela foi mensurada no nível ordinal, utilizando as seguintes categorias: "sempre", "a maioria das vezes", " metade das vezes", " poucas vezes", " nenhuma vez". Foi acrescentada mais uma categoria (N.R.) para contabilizar as poucas questões "não respondidas". O resultado final da tabulação dessa variável resultou em nove votos para a categoria "sempre", 31 votos para a categoria "a maioria das vezes" e dois votos para a categoria "metade das vezes". As categorias "poucas vezes" e "nenhuma vez" não receberam votos. Assim, cada categoria individual da variável foi quantificada segundo o número de votos, ou seja, números inteiros ou discretos, que requerem uma quantificação no nível intervalar.

Por sua vez, esses dados absolutos foram transformados em dados relativos (mensurados no nível racional). Assim percebe-se um equilíbrio das categorias utilizadas para a mensuração das variáveis. Duas categorias mensuram aspectos positivos (ou potencialidades) apontadas pelos alunos ao avaliarem o professor - as categorias "sempre" e "maioria". Duas categorias mensuram 
aspectos negativos (ou fragilidades) - as categorias "poucas" e "nunca". Existe uma categoria neutra, que não se configura como potencialidade nem como fragilidade - a categoria "metade".

Para fins de simplificação da análise, optou-se por um agrupamento das categorias positivas e negativas. Assim, os votos das categorias "sempre" e "maioria" foram somados, constituindo-se em uma nova categoria. De forma análoga, os votos das categorias "poucas" e "nunca" também foram somados, constituindo em uma nova categoria. Os votos da categoria neutra ("metade") foram divididos igualmente entre as duas categorias de forma a manter o equilíbrio.

Levando-se em consideração a maioria das questões relacionadas à maneira como as aulas são ministradas, pode-se perceber a tendência de resultados superiores a $62,5 \%$ e $75 \%$. Isso permite dizer que a qualidade está dentro de padrões vislumbrados nos itens: um, dois, três e quatro. A maioria das questões referentes a aulas, materiais, informações e conteúdos encontram-se avaliada com $89 \%$. Com relação à clareza de conteúdo, nota-se que na maioria das vezes o professor atinge seu objetivo durante as exposições. No item três (informações adequadas), tem-se que $90 \%$ apontam para o índice de excelência, levando-se em consideração que a pesquisa envolveu alunos extremamente críticos com relação a seus mestres e que muitas vezes o professor desperta no aluno sentimentos nada agradáveis e deixa transparecer fraquezas no seu dia-a-dia.

No item quatro (organização das aulas), 82\% das respostas apontaram sempre ou a maioria. Essa informação demonstra que o professor está preocupado com o rendimento de suas aulas e também reafirma os itens anteriores. Assim, pode-se perceber que os professores da IES estudada são: organizados para ministrar suas aulas e preparam suas aulas com clareza na explicação e no conteúdo. Além disso, transmitem informações adequadas e em $71 \%$ das vezes estimulam o interesse em seu alunado. Uma observação a ser feita está relacionada ao $3^{\circ}$ período do curso, que na época da aplicação do questionário, tinha como professores três coordenadores de curso. Nesse referido período, o que se observou foi $100 \%$

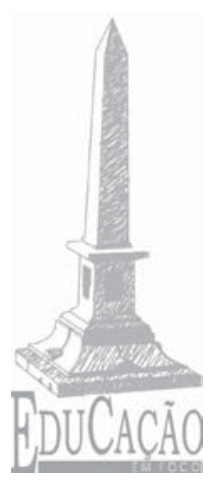

51 
de resposta positiva com relação a todos os professores. Esse índice tem importante papel na análise e pode ser considerado um diferencial do curso, além de interferir no resultado positivo alcançado por todos os docentes.

No caso específico do $3^{\circ}$ período noturno, que possui um total de 15 alunos, cinco questionários foram invalidados, pois destacavam positivamente um professor em especial. Foram aproveitados apenas dez questionários. Essa turma tem um total de seis professores, dos quais três também atuam como coordenadores de outros cursos da instituição. Outro fato importante a ser destacado é o $5^{\circ}$ período noturno, no qual foram descartados quatro questionários em 20 aplicados. Ocorreu um fato parecido com o relatado acima, porém avaliou-se negativamente uma professora. Expressaram-se sentimentos negativos em relação à insatisfação com a falta de visitas técnicas e outros motivos alheios à sala de aula. Outra observação a ser feita está relacionada ao fato dessa professora também ser a coordenadora do curso pesquisado.

No item seis (Estimulam discussões em sala de aula), os professores estimulam pouco as discussões em sala de aula. Talvez para preservar a falta de conhecimento teórico sobre o turismo. Esse fato pode ser também visto pela outra parte da construção do conhecimento, o aluno, como pode ser observado no relato de Barreto: “[...] a maior parte dos alunos desenvolve uma enorme capacidade de crí-

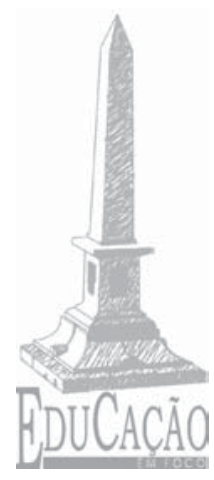

52 tica e discussão, com base no senso comum, sem jamais se apropriar do corpus teórico existente [...]" (BARRETO, 2004, p. 47). Muitas vezes, o aluno se vê diante de uma situação em que utiliza métodos pouco ortodoxos para se expressar. É, nesse ponto, que o professor precisa interferir e demonstrar a realidade em livros e revistas científicas. Dessa forma, o professor neutraliza a ação do aluno. Outro ponto a ser destacado encontra-se nas questões nove, dez e 11, relacionadas ao interesse no aprendizado do aluno. Referem-se à disponibilidade do docente para esclarecimento de dúvidas e/ou demonstração de entusiasmo pelo ensino. Percebe-se que a maioria dos professores desse curso, apesar de não possuir horas de dedicação, 
obteve resultado positivo. Portanto, esse é um dado considerado relevante para a pesquisa e merece destaque.

Vale lembrar que apenas uma professora possui dedicação exclusiva (40 horas), o restante dos professores se enquadra na categoria horista. Como horistas, são pagos apenas para ministrar aulas em determinados horários, dispõem de algum tempo para tirar dúvidas ou esclarecer conteúdos e ainda se importam com o aprendizado dos discentes. Já para a coordenação, a IES oferece 24 horas para as atividades relacionadas à gestão do curso, dentre as quais se podem citar: definir eventos, visitas técnicas para cada período, contratar palestrantes, professores, montar banca para admissão dos mesmos, além de definir trabalhos inter e transdisciplinares referentes a cada período e disciplina envolvida. Além de ser responsável pela divulgação do curso e da instituição junto às diversas escolas de Belo Horizonte, fazendo visitas e distribuindo panfletos nas portas e ainda participar do processo seletivo de forma efetiva.

Ao final de cada semestre, o planejamento para o próximo deverá estar pronto a fim de ser aceito pela direção com os seguintes aspectos: organização; aquisição de equipamentos e livros; visitas técnicas definidas, contendo três orçamentos para cada destino planejado, relacionando cada uma das disciplinas envolvidas e com sugestão de atividade. Contrato e organização de todo o pessoal para o evento da feira gastronômica e cultural, acompanhamento da montagem e desenvolvimento do evento, além da elaboração de lista de convidados. O mesmo ocorre com a entrega dos inventários de cada município, incluindo a confecção do convite às autoridades e a confirmação das presenças. É responsabilidade do coordenador o levantamento das atividades complementares de cada aluno, passando o resultado desse levantamento para o setor de extensão, homologar e certificar cada aluno. Receber discentes para solucionar problemas acadêmicos, além dos professores para dirimir possíveis problemas com alunos e/ou dúvidas acadêmicas, acompanhar de perto seu desenvolvimento. Observar se cada docente fez os lançamentos tanto no diário eletrônico como

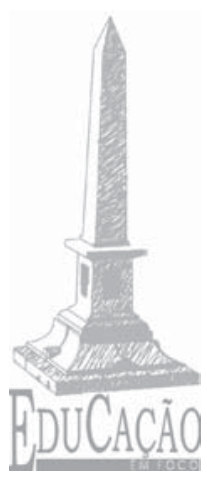

53 
no manual, confrontando as anotações diárias com os planos de ensino de cada disciplina e respectivo período. Quando algum problema for detectado, é o coordenador que chama o docente para que ele possa adequar as informações contidas no documento.

Os itens 12, 13 e 14 contemplam a metodologia utilizada, com materiais inovadores e estudos de casos usados em sala de aula, demonstram que há necessidade de rever esses aspectos, tendo as avaliações abaixo do nível considerado bom, ficando longe do nível de excelência a ser alcançado. No item 15 , que avalia o interesse pela área do curso, há um percentual considerado relevante: $86 \%$ dos docentes sempre ou na maioria das vezes se interessam pelo assunto em questão. Ou seja, a área do curso desperta interesse nos professores, porém não foi avaliado se esse interesse está mais voltado para as orientações ao seu próximo destino quando esse estiver em férias.

A sugestão seria formatar cursos de capacitação para o docente que não tem formação específica na área de turismo. Dessa forma, o profissional teria mais oportunidade e envolvimento com a área focalizada. Acredita-se que o docente poderá propiciar aos discentes oportunidades de criar situações problemas e ter mais argumentação teórica para solucioná-las.

Já nos itens 16 e 17 (Fazem ponte entre sua disciplina e outras; elaboram trabalhos envolvendo outras disciplinas) pode-se verificar que tiveram o mesmo índice de avaliação, entre 60 e $61 \%$, o que indica coerência na avaliação. Os professores conseguem trabalhar envolvendo outras disciplinas. Isso é importante para o curso no geral. O item 18 (Diversificam as atividades em sala) indica que faltam criatividade e inovação no tocante ao dia-a-dia do professor. Quem sabe até se aventurar a ministrar aulas fora da sala, criando novos ambientes e formas de aprendizado.

Ao observar o item 19 (Conhecem a profissão de turismólogo), pode-se verificar um índice razoável de compreensão da profissão de turismólogo avaliado com $61 \%$. Percebe-se que no item 20 , em que se avalia o nível de reconhecimento dos seus deslizes, 
existe uma avaliação negativa com relação à atitude do professor que não admite ter errado ou ter cometido um deslize. Percebe-se que ainda permanece o antigo modelo do professor como ser absoluto naquele determinado assunto e que "ele", o mestre, não comete erros nem tampouco enganos. Concluiu-se que apenas $40 \%$ dos docentes reconhecem seus erros e $60 \%$ poucas vezes reconhecem ou nunca reconhecem.

Gadotti afirma:

Ser professor hoje é viver intensamente o seu tempo, com consciência e sensibilidade. Não se pode imaginar um futuro para a humanidade sem professor. Ele não só transforma a informação em conhecimento e em consciência crítica, mas também forma pessoas. Ele faz fluir o saber, porque constrói sentido para a vida dos seres humanos e para a humanidade e busca, numa visão emancipadora, um mundo mais humanizado, mais produtivo e mais saudável para a coletividade. Por isso eles são imprescindíveis (GADOTTI, 2004, p. 21).

Já no que diz respeito à ética profissional, o item 25 apresenta um sinal de alerta para o que é dito em sala de aula, com destaque para comentários que podem conter conotações dúbias e provocar reações nem sempre interessantes para o curso.

No quesito participação ativa nos eventos do curso, o percentual alcança $71 \%$ de professores que participam dessas atividades. Porém, para que se atinja uma situação de qualidade, seria mais interessante se essa participação fosse acima de 87\%. Assim confirmaria a excelência no sentido da aprovação do evento, além do que os próprios alunos se sentiriam mais comprometidos com os eventos promovidos pelo curso e se sentiriam mais motivados em participar ativamente dos mesmos.

Quanto ao item 27, constatou-se que apenas 54\% dos professores se interessam pelos trabalhos de outras disciplinas. Observa-se um problema, pois em um curso inter e transdisciplinar, essa per-

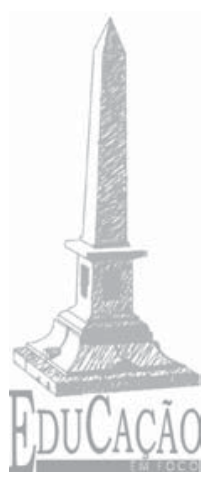

55 
centagem deveria estar acima de $90 \%$, pois dessa forma o objetivo do curso seria alcançado e ficaria mais fácil para o aluno perceber os limites e interfaces das disciplinas. Assim, reforçam-se as questões relacionadas à estrutura curricular do curso de turismo.

O item 29 revela que $74 \%$ dos professores demonstram interesse pela área do curso. Fica aqui o alerta para ser trabalhado junto aos professores: dar maior destaque e visibilidade para a profissão de turismólogo, além de contribuir para o enriquecimento do curso ou ainda de bacharel em turismo. Acredita-se que é importante destacar as áreas em que esse profissional pode atuar, enfocar quais as atividades pode realizar, entre outras ações de reflexão com relação à profissão.

\section{A análise dos dados do questionário docente}

No caso dos docentes, foi aplicado um total de 12 questionários em um universo de 13 professores, sendo excluída a opinião da pesquisadora em questão.

Levando-se em consideração as questões um, dois e três, relacionadas à coordenação e à gestão do curso como um todo, nota-se coerência com as respostas obtidas no questionário dos discentes. Observa-se uma cumplicidade entre professores e coordenação, obtendo-se índices acima de 79\% de aprovação, além da articulação existente entre a coordenação e a direção da IES como um todo.

Em relação à questão quatro, torna-se necessário esclarecer que o projeto pedagógico do curso já foi refeito, e o Plano de Desenvolvimento Institucional (PDI) atualmente está em fase de construção de uma nova versão.

Já os objetivos do curso constantes no Projeto Pedagógico do Curso (PPC) vêm recebendo algumas alterações. Por se tratar de um documento em constante mudança e evolução, ele não pode ser estático. Essas alterações são introduzidas a partir do momento que há evolução dos períodos e das disciplinas a serem ministradas, além das ementas que se encontram também em fase de revisão.

\section{6}

Ano 12 - n. 14 - dezembro 2009 - p. 41-65 
Ao se analisar o perfil do egresso (questão seis), que recebeu $79,2 \%$ em a maioria das vezes ou sempre, observa-se que o corpo docente conhece o projeto pedagógico e está de acordo com o perfil colocado no documento.

No caso específico deste estudo de caso da IES pesquisada, o projeto pedagógico prevê a integração dos conteúdos propostos pela estrutura curricular com novos conceitos e ideias presentes no ambiente externo, cujo estudo possa auxiliar na formação de um egresso atento às transformações da sociedade. Isso se dá por meio da participação do aluno em diferentes eventos oferecidos ao longo do percurso formativo, como disciplinas oferecidas sob a forma de tópicos especiais, participação em congressos internos, visitas técnicas, palestras e minipalestras. Essas são consideradas atividades complementares de graduação, reconhecidas pela IES como complementação do plano de estudos do aluno dentro e fora da instituição.

A adequação e atualização da bibliografia do curso foram avaliadas pelos professores com $87,5 \%$ na categoria maioria das vezes ou sempre. A bibliografia também recebeu nota máxima pelo avaliador do Ministério da Educação (MEC), conceito A, dando ênfase a este quesito, além de proferir alguns comentários relacionados à quantidade de exemplares e títulos. Porém, a biblioteca é um item que merece atenção principalmente quando se inicia o estágio e a confecção da monografia para o final do curso.

O fato de $75 \%$ dos professores avaliarem que no item 18 do questionário há a preocupação com as atividades complementares em seus planos de ensino demonstra um reconhecimento da importância da efetivação dessas horas para a complementação do curso. Porém, o que se percebe é que há uma controvérsia com relação às horas complementares do curso, ou seja, o aluno avaliou que apenas $63 \%$ dos professores têm essa preocupação (item 28 do questionário dos alunos), enquanto que o professor avaliou a mesma pergunta que obteve uma porcentagem de $75 \%$.

No item 19, a IES sofreu uma crítica por parte dos professores no quesito da oferta de eventos acadêmicos direcionados aos mes-

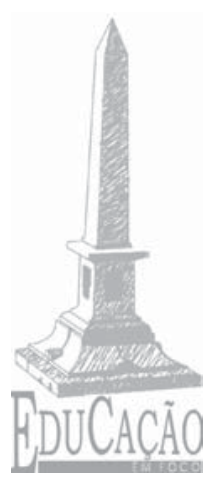

57 
mos. A avaliação, em maioria e sempre, apresentou um índice de $25 \%$, considerado muito abaixo do ideal.

O item 20 (No curso de turismo existem docentes com formação adequada) foi avaliado com 91,7\% na categoria maioria ou sempre, destacando a coerência entre o currículo do professor e a disciplina a ser ministrada por ele. Isso de certa forma enfatiza a importância dessa coerência para o funcionamento do curso e pode ser considerado como um ponto positivo tanto para o curso como para o professor. Há a possibilidade de se fazer a ligação entre o percentual de aprovação no questionário respondido pelo aluno com relação ao docente e sua avaliação geral sobre determinados aspectos tais como: a clareza de conteúdo, materiais e aulas expositivas, características em que os docentes foram muito bem avaliados.

A partir do item 24, o professor avalia todas as turmas do curso e alguns pontos devem ser mais trabalhados: a turma responde bem às aulas ministradas (sendo avaliado em 70,8\%) aponta a necessidade de saber quais os motivos que levam a turma a se interessar mais por determinadas aulas e professores em detrimento de outros. Nesse ponto, sentiu-se a necessidade de maiores esclarecimentos para criar um diagnóstico com mais subsídios para sugestões de atividades e mudança de comportamento.

No item 26 (Atua com comprometimento), o percentual foi ainda menor, atingindo o valor de $66,7 \%$. Sente-se aqui também a necessidade de saber mais profundamente em quais momentos esse comprometimento é falho e em que disciplinas isso é mais sentido.

No quesito 27 (Conhece a profissão de turismólogo), a avaliação de 83,3\% demonstra que, apesar de ser trabalhado todo o semestre em diversas disciplinas, ainda há dúvidas com relação à profissão. Deve ser lembrado que nesse questionário tem-se a opinião dos professores que ministram aulas para o $1^{\circ}$ período e isso pode contribuir para um resultado menor. Mesmo assim, sendo uma profissão com atuações amplas, esse trabalho precisa ser feito com o compromisso de todos os envolvidos no curso.

No item 29 (A turma faz sempre a ponte entre a sua matéria e 
outras), a avaliação de $75 \%$ poderia ser maior se ocorresse um trabalho mais amplo entre as disciplinas, buscando uma integração entre conteúdos e assuntos. Um ponto marcante dessa pesquisa fica na característica percebida com relação à união dos integrantes (item 30), aspecto avaliado com 54,2\%. Se levado em conta que se encontram diariamente e que trabalham sempre em grupos, essa união não é percebida pelos professores. Há sempre relatos dos professores com relação à união ou falta dela em algumas salas do curso. Percebeu-se que acontece a formação de grupos que são rivais entre si, porém com um ponto bem positivo: cada grupo tenta superar o outro em trabalhos apresentados em sala de aula ou ainda entre turmas. É uma competição saudável e que pode ser percebida também em uma das edições da Semana de Turismo, quando cada uma das turmas ofereceu, a partir de um tema, atrações e eventos. Cada turma apresentou em dias específicos e foi sentida certa concorrência entre as turmas.

O item 32 (Apoia e defende os interesses do curso) alcançou um percentual que pode ser considerado bom (75\%). Porém, não expressa o que deve ser melhor trabalhado para atingir uma percentagem maior.

O item 33 (Demonstra apoiar as decisões da diretoria) foi avaliado com $41,7 \%$ e pode expressar um descontentamento relacionado a visitas técnicas. Na maioria das vezes esse tipo de questionário é utilizado para expressar algum tipo de descontentamento.

Os itens 34 e 35, que receberam o mesmo percentual (87,5\%), estão relacionados ao interesse em sua sala de aula e à contribuição de informações e materiais adequados ao conteúdo. Essa avaliação não confirma a avaliação do item 26 do questionário, que se refere ao comprometimento do aluno, nem tão pouco quando relacionado com o próximo item do questionário, o 36, relacionado à organização dos alunos para as aulas, avaliado com 72,7\%. Há ainda outros itens que de certa forma se opõem a esta realidade. Verifica-se que os itens 37 e 38 alcançaram um percentual expressivo (em torno de $85 \%$ ), avaliando o interesse pela matéria minis-

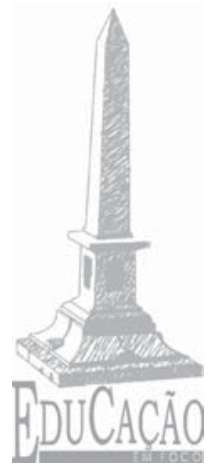

59 
trada e a estimulação do professor em buscar novas informações. Isso de certa forma demonstra que as turmas, de uma maneira geral, mostram interesse e comprometimento para com o curso. Porém, elas sentem-se desconfortáveis ao terem que trabalhar em grupo (item 39), o que deve ser revisto por todos os envolvidos no processo de formação profissional, pois essa profissão requer trabalho em equipe e interdisciplinar.

No item relacionado ao silêncio em sala de aula (item 40), o que se percebe é que são alunos inquietos e ávidos por ações práticas e isso pode causar um grande problema em relação à atitude em sala de aula, interferindo no trabalho daquele docente que tem a sua rotina pautada apenas na teoria e em aulas com práticas discursivas. Esse pode ser o motivo para se refletir sobre a atuação desse discente com relação ao item 42 , que diz respeito à disponibilidade para auxiliar o professor em suas atividades. Esse item obteve um resultado de $70,8 \%$ de poucas vezes ou nenhuma. Nota-se que o docente conhece pouco o mercado turístico (item 48), tecendo poucos comentários a esse respeito. Esse fato levou a pesquisa a atingir um percentual considerado alto no quesito poucas vezes ou nenhuma (87,5\%). É um assunto que deve ser mais trabalhado em sala de aula. Apesar de o curso oferecer palestras além da presença de vários profissionais do trade em eventos do curso, percebe-se ainda a necessidade de uma ação maior a esse respeito.

Outro ponto que merece destaque está na avaliação feita pelo professor com relação à ética dos alunos em sala de aula, que foi bem avaliada, demonstrando que eles possuem uma preocupação com relação aos professores (item 52).

\section{Conclusão}

Com este estudo de caso, pode-se identificar alguns pontos importantes. Dentre eles: o perfil dos alunos levantado tem características que se destacam. Segundo o estudo, parece ser um aluno que precisa estar sempre em movimento, apresenta traços de pes- 
soas empreendedoras. A partir dessas respostas, espera-se que o docente respeite as possibilidades e as trabalhe em sala de aula, aproveitando esse perfil para tornar sua aula mais dinâmica e atraente a partir de atividades movimentadas.

Com relação ao docente que ministra aulas nesse curso, a falta de conhecimento do mercado de turismo pode ser um problema para ser administrado por ele, que poderá se contradizer em exemplos em sala de aula. O coordenador do curso poderá trabalhar esse ponto a partir de debates, reuniões e até visitas dos professores ao mercado turístico e ainda oferecer textos e/ou artigos que tratem do assunto.

Com relação à direção, entende-se que as visitas técnicas são de grande importância para o curso e espera-se que seja ofertado o maior número possível dessa atividade ao aluno, que precisa da vivência para ter sucesso na carreira.

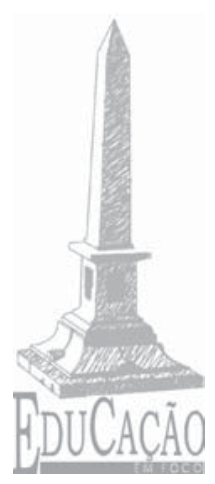

61 


\section{Referências}

ANSARAH, M. G. dos R. Formação e capacitação do profissional em turismo e hotelaria: reflexões e cadastro das instituições educacionais no Brasil. São Paulo: Aleph, 2002. 202 p.

BRASIL. Congresso Nacional. Lei n. 9.394, de 20 de dezembro de 1996. Estabelece as Diretrizes e Bases da Educação Nacional.

Diário Oficial da República Federativa do Brasil. Brasília, DF, v. 134, n. 248, p. 27.833-27.841, 23 dez. 1996. Disponível em: <http:/ / www.planetaeducacao.com.br/novo/legislacao/ldb.pdf $>$. Acesso em: 21 abr. 2007.

COOPER, C.; et al. Turismo: princípios e prática. Porto Alegre: Bookman, 2001. 559 p.

EMBRATUR - Instituto Brasileiro de Turismo. Disponível em: < www.embratur.gov.br>. Acesso em: 22 mar. 2007.

GIL, A. C. Didática do ensino superior. São Paulo: Atlas, 2007. 283p.

GO, F. M. A globalização e os problemas educacionais do turismo emergente. In: THEOBALD, W. F. (Org.) Turismo global. 2. ed. São Paulo: Senac, 2002. 510 p.

LIBÂNEO, J. C; OLIVEIRA, J. F. de; TOSCHI, M. S. Educação escolar: políticas, estrutura e organização. São Paulo: Cortez, 2003. 408p.

MASETTO, M. T. Competência pedagógica do professor universitário. São Paulo: Summus, 2003. 194 p.

MATIAS, M. Turismo: formação e profissionalização. São Paulo: Manole, 2002. 106 p. 
PIAGET, J.; GRÉCO, P. Aprendizagem e conhecimento. Rio de Janeiro: Freitas Bastos, 1974.185p.

TEIXEIRA, G. O processo ensino aprendizagem e o papel do professor como gestor do pensar. In: Ser professor universitário.

Disponível em: <www.serprofessoruniversitario.pro.br/ ler.php?modulo=7\&texto=1506>. Acesso em: 21 abr. 2007.

VYGOTSKY, L. S. Pensamento e linguagem. Tradução de M. Resende. Lisboa: Antídoto, 1979.213p.

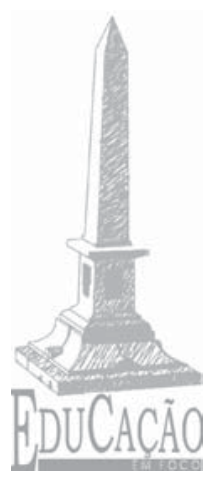




\title{
Teacher's roll in the development of the tourism bachelor
}

\begin{abstract}
The present study analyses the importance of the professor's role in the Tourism Course, his interference, contribution and participation in the formation of the bachelor in Tourism, besides the student's perception of this professor. This subject has caught my interest since my college times when I could notice that the interest of the college students was directly proportional to the acts of the educational staff. When I started my career as a professor I noticed that some colleagues arouse in their students the same interest before observed in college times. So the objective of this study was to investigate the interference a professor might have in the process of professional formation besides evaluating the perception of the professor regarding the students. For this reason it was made the analyses of the data recovered from the applications of 42 valid questionnaires, containing 29 questions, applied to the students. This percentage allows some clear considerations about the profile and objective of the Faculty Memory in the studied course. To the professors 12 questionnaires out of 13 were applied, containing 52 questions. These questionnaires supplied information about the professors' contribution to the course; to the infra-structure of the IES; to the educational project along with, the value of the evaluation process during the formation of the student. The results of the studies confronted with the bibliographical reference used, revealed some information that could be prominent. Such as: the professors of the mentioned course were highly scored concerning the previous preparation of classes, almost unanimity, and the clear explanations and adequate information given. Other point observed
\end{abstract}


was the fact of having professors that also work as coordinators of other courses, to teach in the Tourism course.

Such strategy has had a positive effect up to now, such as the awareness of this teacher in the growth and development of the student as a whole. Such professionals besides having effectively participated in the Educational Project they have a wide knowledge of the IES, which contributed even more to the systematic vision of the course. It is important to highlight that the infra-structure made available by the IES studied contributed positively to the students satisfaction in relation to the course and to the activities proposed in the laboratories along with the execution of the inventories and events idealized by the students. Therefore it is important to emphasize that the exploratory aspect of this study opens the possibility of accomplishment of many other new studies about the role of professors in the Tourism Course. It has been concluded that there is a need to call the attention of the professors of this course to: the profession itself and the area the graduate student could get into due to participation in courses, congresses and fairs, along with effective participations in the activities promoted during the course.

Keywords: Tourism; educational staff; college students; educational project.

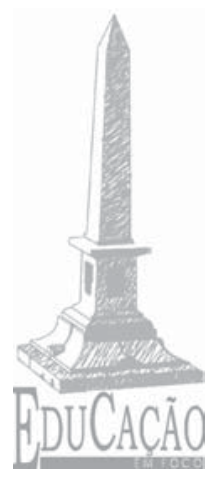

